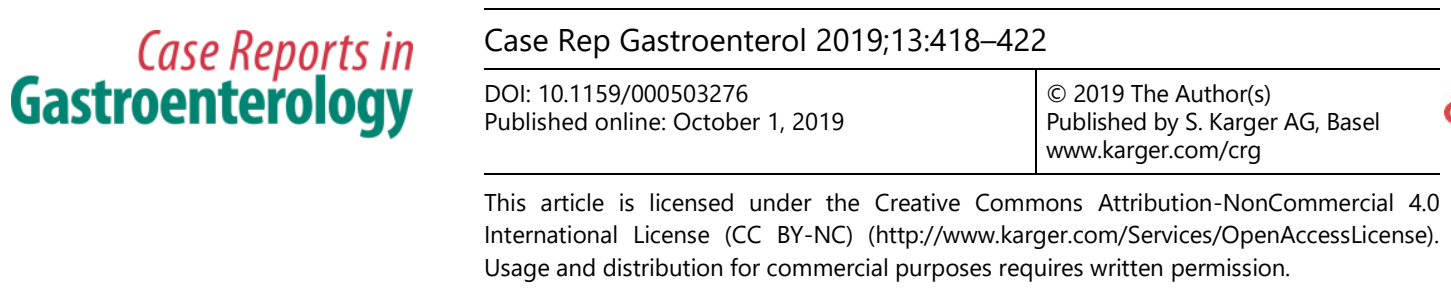

\title{
Endoscopic Resection of a Pedunculated Cavernous Hemangioma of the Sigmoid Colon: A Case Report
}

\author{
Naotaka Ogasawara Manami Suzuki Kazunori Adachi \\ Yoshiharu Yamaguchi Sayuri Yamamoto Yasutaka Hijikata \\ Masahide Ebi Yasushi Funaki Makoto Sasaki Kunio Kasugai \\ Department of Gastroenterology, Aichi Medical University School of Medicine, \\ Nagakute, Japan
}

\section{Keywords}

Cavernous hemangioma $\cdot$ Clipping $\cdot$ Colon $\cdot$ Pedunculated type $\cdot$ Polypectomy

\begin{abstract}
Hemangiomas are common benign tumors that usually occur on the head and neck in children. However, colonic hemangiomas are rare in clinical practice. Approximately $80 \%$ of colonic hemangiomas are of the cavernous type, and morphologically, $\geq 80 \%$ of colonic hemangiomas are sessile and semi-pedunculated. Notably, pedunculated colonic hemangiomas are rare. A 69-year-old woman presented with hematochezia and underwent colonoscopy, which revealed a soft pedunculated submucosal tumor (SMT) measuring $1.5 \mathrm{~cm}$ in diameter, in the sigmoid colon. The surface of the SMT resembled the surrounding normal colonic mucosa with regard to color and appearance, with multiple red patches. Narrow-band imaging revealed a few telangiectasias on the surface of the SMT. The lesion could not be definitively diagnosed based on endoscopic findings. Therefore, for more accurate diagnosis, the SMT was removed by snare polypectomy with electrocautery after clipping the basal portion of the tumor stalk for prophylactic hemostasis. Histopathological examination of the specimen revealed a cavernous hemangioma with a negative resection margin. We report a case of a pedunculated cavernous hemangioma of the sigmoid colon removed by snare polypectomy with electrocautery after clipping the basal portion of the tumor stalk for prophylactic hemostasis.
\end{abstract}




\section{Case Reports in Gastroenterology}

Case Rep Gastroenterol 2019;13:418-422

DOI: $10.1159 / 000503276$

(c) 2019 The Author(s). Published by S. Karger AG, Basel www.karger.com/crg

Ogasawara et al.: Endoscopic Resection of a Pedunculated Cavernous Hemangioma of the Sigmoid Colon: A Case Report

\section{Introduction}

Hemangiomas are common benign tumors that usually occur on the head and neck in children [1]. Colonic hemangiomas are rarely observed in clinical practice, although hemangiomas can originate at any site throughout the gastrointestinal tract [2]. These vascular malformations are clinically important owing to the risk of massive bleeding associated with these lesions. Approximately $17 \%$ of colonic hemangiomas cause complete or partial intestinal obstruction secondary to significant luminal narrowing, intussusception, or volvulus [3, 4]. Reportedly, preoperative histopathological diagnosis is challenging because of hemorrhage associated with manipulation during biopsy. Therefore, diagnosis is usually confirmed by macroscopic evaluation of lesions during endoscopy [2]. Several histological and clinical types of hemangioma are described in the literature; however, the cavernous and capillary subtypes are the most common. Notably, 61 and $23 \%$ of colonic hemangiomas are sessile and semipedunculated, respectively [5], and pedunculated colonic hemangiomas are rare. Endoscopic resection techniques such as endoscopic mucosal resection [6], endoscopic submucosal dissection [7], and endoscopic polypectomy [5, 8] have recently been reported for the management of gastrointestinal hemangiomas.

We report a case of a pedunculated cavernous hemangioma of the sigmoid colon removed by snare polypectomy with electrocautery after clipping the basal portion of the tumor stalk for prophylactic hemostasis.

\section{Case Report}

A 69-year-old woman presented with hematochezia and underwent colonoscopy, which revealed a soft pedunculated submucosal tumor (SMT) measuring $1.5 \mathrm{~cm}$ in diameter, in the sigmoid colon (Fig. 1a). The surface of the SMT resembled the surrounding normal colonic mucosa with regard to color and appearance, with multiple red patches (Fig. 1a). Narrowband imaging revealed a few telangiectasias on the surface of the SMT (Fig. 1b); however, additional characteristics of the SMT could not be determined. The lesion could not be definitively diagnosed based on the endoscopic findings. Therefore, the SMT was removed by snare polypectomy with electrocautery after clipping the basal portion of the tumor stalk for prophylactic hemostasis, for more accurate diagnosis (Fig. 1c, d). Histopathological examination of the specimen revealed that the SMT was covered by normal colonic mucosa (Fig. 2a, b) and showed numerous dilated blood vessels in the mucosa and submucosa (Fig. 2a, b). The vascular epithelium of the dilated vessels did not reveal any malignant changes. Edematous stroma was observed in the submucosa. The SMT was diagnosed as a cavernous hemangioma (Fig 2a, b) with a negative resection margin.

\section{Discussion}

Hemangiomas are common soft tissue tumors ( $7 \%$ of all benign tumors) and constitute the most common tumors that occur during infancy and childhood [9]. Most hemangiomas are superficial lesions with a predilection for the head and neck region; however, they can occasionally originate in the gastrointestinal tract [9]. Colonic hemangiomas are benign lesions originating from the submucosal vascular plexus secondary to embryonic sequestration of the mesodermal tissue $[3,10]$. Gastrointestinal hemangiomas occur more commonly in the small intestine or stomach than in the large intestine. Most colonic hemangiomas are located in the rectum and sigmoid colon [11]. No universally accepted theory can explain the etiopathogene- 
sis and pathophysiology of hemangiomas or all characteristics of these lesions, such as the predilection for the female sex, typical occurrence after birth, spontaneous involution, abnormal tissue architecture, and association with developmental field disturbances. Hemangiomas perhaps represent the final common expression of several pathophysiological mechanisms that occur alone or in combination [12,13]. The World Health Organization has classified hemangiomas into the capillary, cavernous, arteriovenous, venous, intramuscular, and synovial subtypes [14]. Approximately $80 \%$ of colonic hemangiomas are cavernous hemangiomas [15], and capillary hemangiomas account for less than $10 \%$ of these colonic lesions [10]. Cavernous hemangiomas consist of large blood-filled spaces or sinuses lined by single or multiple layers of endothelial cells [11]. Cavernous hemangiomas are accompanied by bleeding (6090\%), anemia (43\%), obstruction (17\%), and occasional platelet sequestration [15], whereas capillary hemangiomas are usually solitary and asymptomatic lesions. Notably, $61 \%$ and $23 \%$ of colonic hemangiomas are sessile and semi-pedunculated, respectively [5]. However, pedunculated colonic hemangiomas are rare. Previous studies have reported a polypoid colonic hemangioma removed by endoscopic mucosal resection [6] and a pedunculated colonic hemangioma removed by endoscopic submucosal dissection [7]. To our knowledge, 2 previous reports have described endoscopic polypectomy for removal of colonic hemangiomas $[5,8]$; however, these reports could not be identified after a PubMed (National Library of Medicine) search. Reportedly, one of these was published in the Japanese literature [5]. A PubMed database search did not yield any reports describing a pedunculated colonic hemangioma removed by complete endoscopic snare polypectomy after clipping the basal portion of the tumor stalk.

Snare polypectomy with electrocautery after clipping the basal portion of the tumor stalk is a useful technique for prophylactic hemostasis.

\section{Statement of Ethics}

The authors have no ethical conflicts to disclose. Informed consent was obtained from the patient.

\section{Disclosure Statement}

The authors declare no conflict of interest.

\section{References}

1 Drolet BA, Esterly NB, Frieden IJ. Hemangiomas in children. N Engl J Med. 1999 Jul;341(3):173-81.

2 Pontecorvo C, Lombardi S, Mottola L, Donisi M, DiTuoro A. Hemangiomas of the large bowel. Report of a case. Dis Colon Rectum. 1983 Dec;26(12):818-20.

3 Head HD, Baker JQ, Muir RW. Hemangioma of the colon. Am J Surg. 1973 Nov;126(5):691-4.

4 Utsumi K, Ogasawara N, Sasaki M, Hijikata Y, Masui R, Ito Y, et al. Intussusception in a child caused by capillary hemangioma of the colon. Clin J Gastroenterol. 2010 Apr;3(2):83-7.

5 Suzuki T, Suzuki T, Shinoda M, et al. A case of colonic cavernous hemangioma treated with endoscopic polypectomy in combination with the ligating device. Gastroenterological Endoscopy. 2004;46:2409-15.

6 Hasegawa K, Lee WY, Noguchi T, Yaguchi T, Sasaki H, Nagasako K. Colonoscopic removal of hemangiomas. Dis Colon Rectum. 1981 Mar-Apr;24(2):85-9.

7 Chen K, Yan M, Liu F. Successful endoscopic submucosal dissection of a large cavernous hemangioma in the colon. Endoscopy. 2019 Jul;51(7):E195-6.

8 Kiba T, Takemura M. Polypoid cavernous hemangioma removed under colonoscopy. Dig Endosc. 2003;15(4):338-40. 
Ogasawara et al.: Endoscopic Resection of a Pedunculated Cavernous Hemangioma of the Sigmoid Colon: A Case Report

9 Bailey KA, Wales PW, Gerstle JT. Laparoscopic versus open reduction of intussusception in children: a singleinstitution comparative experience. J Pediatr Surg. 2007 May;42(5):845-8.

10 Lyon DT, Mantia AG. Large-bowel hemangiomas. Dis Colon Rectum. 1984 Jun;27(6):404-14.

11 Levy AD, Abbott RM, Rohrmann CA Jr, Frazier AA, Kende A. Gastrointestinal hemangiomas: imaging findings with pathologic correlation in pediatric and adult patients. AJR Am J Roentgenol. 2001 Nov;177(5):1073-81.

12 Aziz A, Kane TD, Meza MP, Vaughan KG, Hackam DJ. An unusual cause of rectal bleeding and intestinal obstruction in a child with peripheral vascular malformations. Pediatr Surg Int. 2005 Jun;21(6):491-3.

13 Bauland CG, van Steensel MA, Steijlen PM, Rieu PN, Spauwen PH. The pathogenesis of hemangiomas: a review. Plast Reconstr Surg. 2006 Feb;117(2):29e-35e.

14 Fletcher C, Unni K, Mertens F. World health organization classification of tumors: Pathology \& genetics: Tumours of soft tissue and bone. IARC Press; 2002. pp. 320-1.

15 Hsu RM, Horton KM, Fishman EK. Diffuse cavernous hemangiomatosis of the colon: findings on threedimensional CT colonography. AJR Am J Roentgenol. 2002 Oct;179(4):1042-4.
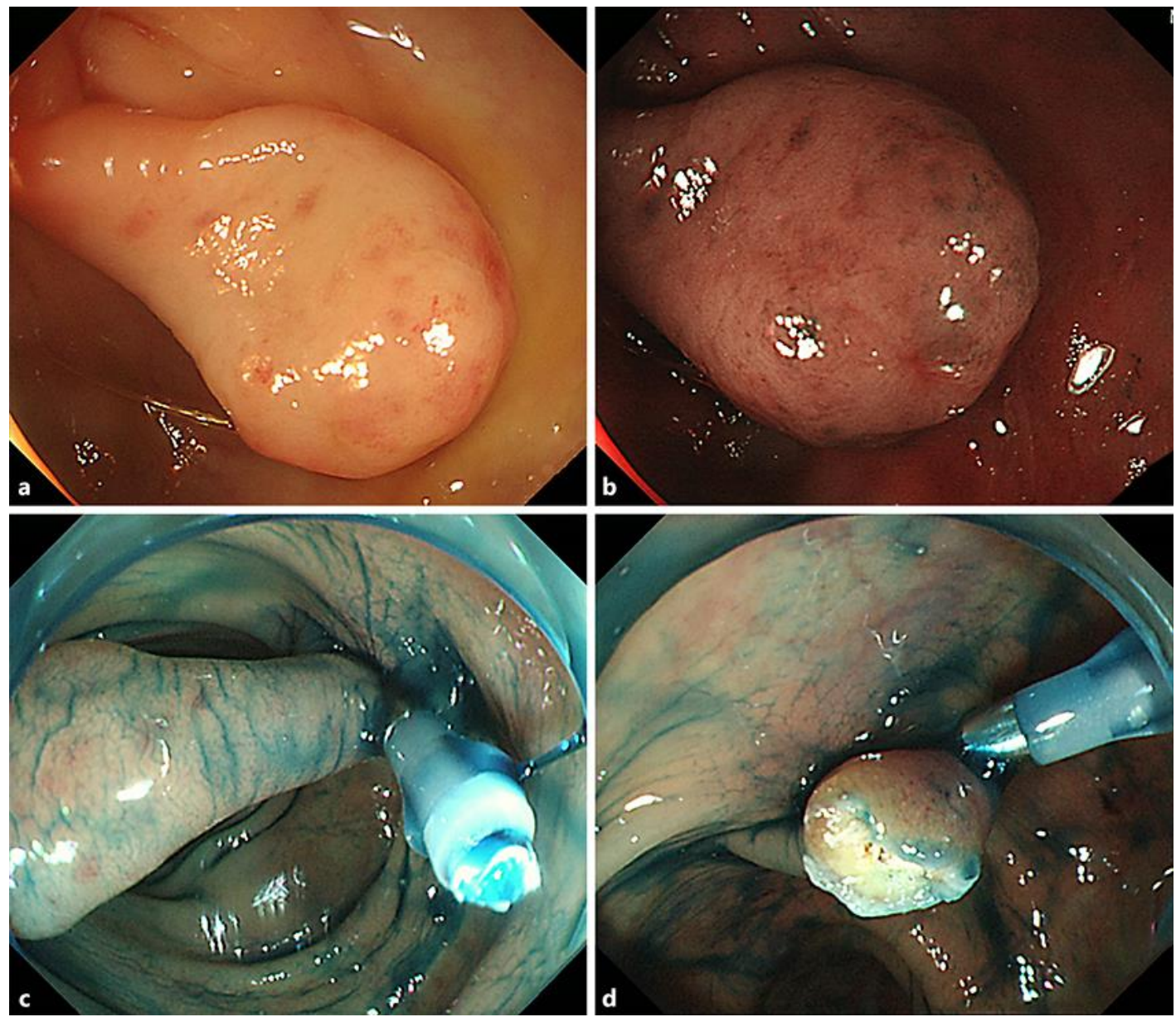

Fig. 1. Endoscopic image showing an SMT measuring $1.5 \mathrm{~cm}$ in the sigmoid colon. The lesion is covered by normal colonic mucosa with multiple small red patches (a). Endoscopic images of narrow-band imaging showing an SMT with a few telangiectasias on the surface (b). Clipping of the basal portion of the tumor stalk of the SMT performed to prevent post-polypectomy bleeding (c). The SMT is removed by snare polypectomy with electrocautery (d). SMT, submucosal tumor. 


\section{Case Reports in Gastroenterology}

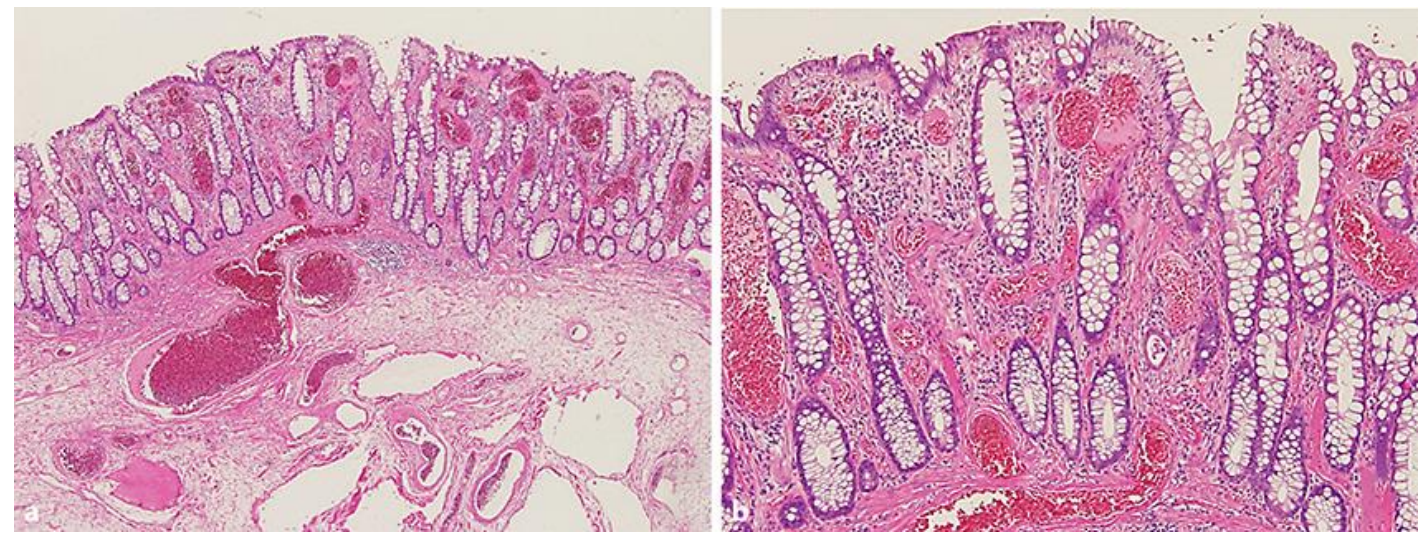

Fig. 2. Histopathological examination of the resected SMT specimen. The SMT is covered by normal colonic mucosa. Numerous dilated blood vessels are visualized in the mucosa and the submucosa. The vascular epithelium of the dilated vessels shows no malignant changes. Edematous stroma is observed in the submucosa. The lesion shows a negative resection margin. Magnification: $\times 100$ (a) and $\times 200$ (b). SMT, submucosal tumor.

Ogasawara et al.: Endoscopic Resection of a Pedunculated Cavernous Hemangioma of the Sigmoid Colon: A Case Report 